\title{
O CONCEITO DE LÍNGUA GERAL DE MINA: APONTAMENTOS PARA A COMPREENSÃO DE SEU SIGNIFICADO HISTÓRICO
}

Ivana Stolze LIMA ${ }^{1}$

\section{DOI: http://dx.doi.org/10.21165/gel.v18i3.3277}

Resumo: O artigo propõe uma análise do conceito "língua geral de Mina", a partir de sua ocorrência no título de um dos mais importantes registros sobre línguas africanas no Brasil (Obra Nova da Língua Geral de Mina, de Antonio da Costa Peixoto, 1731 e 1741) e incorporando ocorrências similares e elaborações pertinentes à questão linguística em documentos históricos relacionados ao tráfico atlântico e escravização de povos africanos falantes de línguas gbe. Lança mão de historiografia já disponível e dialoga com estudos da área de história linguística, buscando uma perspectiva transdisciplinar. A principal hipótese é apontar tal conceito como um constructo português, através do qual a diversidade linguística dos povos envolvidos pelo tráfico e escravização foi enfrentada. Ao mesmo tempo, busca contribuir para a compreensão da experiência dos povos africanos escravizados, sua possibilidade de resistir e reconstruir vínculos sociais e comunitários.

Palavras-chave: Língua Geral. Línguas Gbe. Tráfico atlântico. Escravidão. Línguas Africanas no Brasil.

\footnotetext{
1 Fundação Casa de Rui Barbosa (FCRB), Rio de Janeiro, Rio de Janeiro, Brasil, ivana@rb.gov.br;
} http://orcid.org/0000-0001-6488-1036 
- | O conceito de língua geral de Mina: apontamentos para a compreensão de seu significado histórico

\section{THE CONCEPT OF "LÍNGUA GERAL DE MINA": NOTES ON ITS HISTORICAL MEANING}

Abstract: The article proposes an analysis of the concept "língua geral de Mina" or General Language of Mina, based on its occurrence in the title of one of the most important records about African languages in Brazil (Obra Nova da Língua Geral de Mina, by Antonio da Costa Peixoto, 1731 and 1741). It includes an examination of similar occurrences of the concept, and elaborations pertinent to linguistic issues of the Atlantic slave trade and enslavement of African gbe-speaking peoples. It seeks a transdisciplinary approach between social history and linguistic history. The main hypothesis points to this concept as a Portuguese construct, through which the colonial agents faced the linguistic diversity of the peoples involved in the trade and in enslavement. At the same time, it seeks to contribute to the understanding of the experience of enslaved African peoples, as well their ability to resist and rebuild social and communal ties.

Keywords: General Language. Gbe Languages. Atlantic Slave Trade. Slavery. African Languages in Brazil.

\section{Introdução}

Esse artigo busca discutir o conceito histórico de língua geral de Mina. Antonio da Costa Peixoto (Felgueiras, Portugal, 1703 - Ouro Preto, 1763), que foi um escrivão e juiz da vintena na área mineradora, intitulou e datou os seus dois manuscritos que sobreviveram nos arquivos. O mais antigo, de 1731, chamou de Obra nova de lingoa minna, traduzida ao nosso igdioma portuguez ${ }^{2}$. O segundo documento, de 1741, tem o título Obra nova de lingoa geral de mina, traduzida, ao nosso igdioma. Assim, trata-se quase do mesmo título em duas edições - manuscritas - de uma obra, que seguem a mesma estrutura básica na sua concepção e ordenamento, sendo que a de 1741 tem mais itens, frases e diálogos do que a primeira, além de outros elementos diferenciais.

Como interpretar o sentido de língua mina, ou língua geral de Mina, nos títulos dos documentos de 1731 e 1741? A análise que proponho objetiva problematizar seu significado

\footnotetext{
2 No documento original, que consultei no acervo de reservados da Biblioteca Nacional de Lisboa, esse título foi riscado, e foi atribuído, por Antonio Ribeiro dos Santos (1745-1818), bibliotecário-mor da então Real Biblioteca Pública da Corte, o título Alguns apontamentos da lingoa minna com as palavras portuguezas correspondentes. A identificação da letra de Antonio Ribeiro dos Santos foi apontada pela bibliotecária Ana Cristina de Santana Silva, quando me atendeu em julho de 2018. Ultrapassar sua rasura, que aliás cobriu outros trechos do documento, e cuja motivação pretendo explorar em outro trabalho, é importante para recuperar a continuidade entre os dois manuscritos.
} 
na tessitura histórica que os produziu, investigando sua ocorrência e relacionando-a a outros registros históricos sobre aspectos linguísticos dos povos gbe. Serão explorados, em perspectiva transdisciplinar, a historiografia e os estudos linguísticos pertinentes à questão ${ }^{3}$. Alguns elementos importantes da dimensão linguística da escravização de homens e mulheres podem ser evidenciados por essa abordagem, além de melhor perceber as implicações do que o raro registro elaborado por Antonio da Costa Peixoto e seus prováveis coautores anônimos têm a nos dizer, como um complemento ou contraponto a trabalhos já publicados sobre o documento. Pretende-se, com essa discussão, contribuir para o conhecimento acerca da experiência de povos africanos da chamada diáspora mina no Brasil, marcada pela violência da escravização, bem como pela possibilidade de resistir e reconstruir vínculos sociais e comunitários.

\section{O conceito de língua geral de Mina e outras representações do tráfico e escravização na área gbe}

É fato que a expressão consiste em uma representação portuguesa do que os próprios portugueses denominaram língua geral de Mina. Trata-se assim de um constructo intelectual-cognitivo, parcialmente exterior, forjado pelas relações principalmente comerciais travadas com a Costa da Mina, baseadas no tráfico de homens e mulheres, na circulação de tabaco, de ouro, de búzios, de aguardente, de armas, de tecidos e outros produtos. O conceito de Costa da Mina, através do qual a região era apreendida pelos portugueses; a categoria mina, a forma genérica de designar os povos; e o conceito de língua mina ou língua geral de Mina compõem esse projeto econômico-colonial. Seu conteúdo aponta para a expectativa de que haveria, entre os africanos traficados, uma possibilidade de comunicação. A montagem do tráfico na região, parte de um sistema atlântico que funcionou a ponto de gerar milhares de homens e mulheres traficados a cada ano, contou com essa expectativa.

O conhecimento linguístico atual considera a paisagem linguística da região a partir da discussão do conceito de línguas gbe, que se baseia na semelhança tipológica entre tais línguas, na verificação da possibilidade de intercompreensão entre seus falantes, na

\footnotetext{
3 Não faz parte do escopo deste artigo discutir os debates da linguística contemporânea sobre as possíveis definições e ressignificações do conceito de língua geral, os quais aliás se debruçam mais frequentemente sobre sua relação com as línguas dos povos ameríndios. No entanto, pode ser que a discussão aqui tratada contribua para tais debates, na medida em que busca entender o sentido histórico da expressão, presente em registros documentais, em sua formulação específica - língua geral de Mina. Certamente alguns contrapontos com o uso histórico do conceito "língua geral" quando referido às línguas ameríndias serão pertinentes para o problema aqui recortado. Além disso, alguns trabalhos da área de linguística histórica estão na base da investigação aqui proposta e serão apontados ao longo do artigo.
} 
- | O conceito de língua geral de Mina: apontamentos para a compreensão de seu significado histórico

hipótese de um possível proto-idioma gbe ${ }^{4}$. O conceito gbe foi incorporado por outras áreas, como a história e a antropologia, como um determinado nível de abordagem para a consideração dos povos envolvidos como "gbe falantes", assim como para a região da sua ocorrência como "área gbe", sem desconsideração das especificidades e dinâmicas próprias ${ }^{5}$. Por área gbe, entende-se uma faixa territorial que vai da região fronteiriça entre Gana e Togo, atravessa o Togo e o Benim, até parte da Nigéria, e do litoral até cerca de 200 quilômetros para o interior.

O historiador Carlos Silva Jr. foi quem identificou uma demanda específica por homens e mulheres daquela área linguística, apontando que, dentre outros aspectos de um sistema complexo que envolvia diferentes interesses e agentes do tráfico, a possibilidade de comunicação animava tal demanda. Isso teve impacto violento sobre as relações entre os povos da região, com a reconfiguração e fortalecimento de reinos pelos interesses do tráfico.

A demanda das Américas por escravos de grupos étnico-linguísticos específicos amplificou processos sociais já em curso no Golfo do Benim. Entre eles, o crescimento dos conflitos com reinos rivais e das razias sobre comunidades vizinhas. Embora os métodos de obtenção de escravos fossem variados punições judiciais, vingança contra adversários políticos, não pagamento de dívidas, penhora humana, acusações de feitiçaria, razias e sequestros --, os conflitos bélicos foram o mecanismo básico. (SILVA Jr., 2020, p. 36).

Como escreve esse pesquisador, a história da escravização na região foi de uma violência "linguisticamente orientada, avançando sobre os grupos gbe-falantes" (SILVA Jr., 2020, p. 36). Carlos Silva apresenta um panorama da "diáspora mina-gbe", apontando que já no século XVI havia comércio atlântico de escravizados no Golfo do Benim, levando povos falantes de gbe às Américas. Ingleses levaram-nos a Barbados, e Jamaica, desde a segunda metade do século XVII e durante todo o século XVIII. Para o Haiti (então São Domingos), foram levados pelos navios franceses ao longo do século XVIII. Para Cuba, principalmente no século XIX, até quase 1870, pela produção açucareira. Estavam

\footnotetext{
4 Retomarei esse debate na segunda parte do artigo.

5 A expressão área gbe ajuda a enfrentar a diversidade de representações geográficas e denominações que os povos europeus construíram sobre a região, bem como a historicidade das fronteiras dos Estados nacionais após a independência dos atuais Benim, Togo, Gana, Nigéria. Um dos pesquisadores que lança mão e explica sua utilização é Parés (2007). Outro exemplo é Sweet (2011). O conceito de área gbe é útil, mas deve ser utilizado com cuidado, pois se trata de uma área multilíngue, que tem a presença de línguas de outras famílias. No Benim, por exemplo, há também as línguas de outros grupos, como bariba, dendi, ditamari e iorubá, como assinala Kluge (2007).
} 
também na Louisiana e Costa Rica (SILVA Jr., 2020). A presença dos falantes de línguas gbe foi importante também na gênese de línguas crioulas como as do Suriname, e Haiti $(\mathrm{ABOH}, 2015)$. Suas estimativas apontam que, durante o século XVIII, do total de 1.284.00 africanos levados do Golfo do Benim para as Américas, 72\% eram falantes de línguas gbe (SILVA Jr., 2020).

Embora provavelmente anterior, em 1553 há notícias do contato de portugueses com povos gbe do litoral, envolvidos com a produção de pesca, sal e com o comércio (PARÈS, 2007). O tráfico da área gbe para as áreas de colonização portuguesa já existia desde o século XVI, se tornou constante no século XVII, e deslanchou em um ritmo altíssimo com o início da mineração do ouro e metais e pedras preciosas no final daquele século. Além da significativa concentração demográfica nas Minas Gerais, estiveram em outros centros urbanos e zonas rurais, uma vez que a mineração teve efeitos econômicos nas demais regiões. Estiveram na produção de açúcar e tabaco da Bahia, nos caminhos do sertão, em Pernambuco, no Rio de Janeiro, na região platina, no Maranhão e Grão Pará.

No século XVII, o reino de Aladá (comumente referido na documentação em português como Arda) se configurou como um dos mais importantes reinos escravistas do tráfico transatlântico, e sua relação com Portugal data já do século anterior. Serafim Leite, na sua História da Companhia de Jesus no Brasil, menciona a existência de um "Catecismo da língua dos ardas", elaborado por um padre angolano que viveu no Brasil, Manoel de Lima (Luanda, c. 1667 - Salvador, 1718) e que, além de ser perito na língua de Angola, teria sido um "apóstolo dos Ardas", mas essa obra estaria hoje perdida (LEITE, 1949). Se por um lado pode-se tratar de um equívoco (ZWARTJES, 2011), trata-se de um indício verossímil, dada a preocupação jesuítica em doutrinar os africanos em suas línguas, a presença significativa de pessoas ardas no período, e o fato de que foi comum a produção de catecismos manuscritos para uso dos padres. Outro catecismo dirigido aos ardas, tendo sido esse impresso, foi feito em espanhol, pelo padre capuchinho José de Najera, em 1658, a Doctrina Christiana, y explicacion de sus misterios, en nuestro idioma Español, y en lengua Arda (LABOURET; RIVET, 1929). Servindo também como vocabulário, como aponta uma nota no início da edição, esse é provavelmente o primeiro instrumento linguístico europeu, impresso, sobre uma língua gbe.

Outro vínculo entre o tráfico de escravizados e o mapeamento linguístico da região aqui focalizada pode ser visto pela atuação de Jean Barbot (1655-1712), um traficante francês, que atuou no tráfico britânico e elaborou um pequeno vocabulário do que 
- | O conceito de língua geral de Mina: apontamentos para a compreensão de seu significado histórico

chamou as "principais línguas faladas na costa da Guiné": as dos geloffs (jolofos?), a dos foulles (fulas?), a da Costa do Ouro e, em uma só coluna, como uma mesma língua, a de Uidá e Aladá, que ele teria recolhido em Uidá. A partir de uma lista de palavras em inglês, em ordem alfabética, Barbot enumera as correspondentes naquelas línguas (BARBOT, 1732; LAW, 1992).

Outro documento que apresenta a tentativa de domínio linguístico pelos interesses do tráfico de humanos e demais relações comerciais sobre os povos falantes de gbe é a Grammaire abbrégée, ou entretien en langue française et celles des Nègres de Juda, cujo título e subtítulo são bastante diretos: Gramática abreviada, ou entrevista na língua francesa e na dos Negros de Vidá, muito útil aos que fazem o comércio de Negros nesse Reino, e para os cirurgiões das embarcações, para interrogar os Negros quando estão doentes, e que pode servir para compor um pequeno Dicionário (LABAT, 1730, capa, tradução nossa) ${ }^{7}$. Produzido na década de 1720, quando então Uidá já era um dos portos importantes do embarque de cativos, é um vocabulário que compreende cerca de 80 frases curtas relativas a comércio, saúde, corpo humano, alimentação, numeração (LABAT, 1730; LABOURET; RIVET, 1929).

Um outro exemplo de registros elaborados por agentes envolvidos com o tráfico, escravização ou doutrinação é o de Christian Oldendorp, uma história das missões nas ilhas caribenhas, publicado em alemão em 1777. Há uma lista de itens lexicais em várias línguas africanas que o missionário recolheu nas ilhas, dentre as quais línguas gbe nomeadas por ele como watje e papaa (OLDENDORP, 1987).

Uma dimensão comum pode ser identificada a partir de relatos como os de Barbot, Labat, Oldendorp, Dalzel e o conceito português de língua geral: todos esses agentes europeus envolvidos com o tráfico e escravização estiveram atentos à possibilidade de intercompreensão. Essa era uma questão decisiva, ainda que eles próprios não conseguissem decodificar tais línguas. Barbot escreve, ao tratar da Costa do Ouro, de duas

\footnotetext{
6 BARBOT, Jean. Description of the Coasts of North and South Guinea. 1732. Ver o tópico "Vocabulary of words, names, and phrases, in the languages of the Geloffs, Foulles, Gold Coast, Fida, and Ardra", p. 416-420. Há um manuscrito em francês que não foi publicado, de 1688, e uma tradução publicada em inglês em 1732, mas baseia-se em viagens feitas no século XVII, além de relatos de outros viajantes. Sobre essa fonte, ver Law (1992).

7 No original: “[...] très utile à ceux qui font le commerce des Noirs dans ce Royaume, et pour les Chirurgiens des Vaisseux, pour interroger les Noirs lorsqu'ils sont malades; ce qui peut servir pour composer un petit Dictionnaire".

8 O watje pode ser o aja, e o papaa, o autor diz que seria o nome correto do reino do Popo. A publicação original é: OLDENDORP, Christian. Geschichte der Mission der Evangelischen Brüder auf den Caraibischen Inseln, S. Thomas, S. Croix, und S. Jan. 1777. Utilizamos a edição em inglês: OLDENDORP, C. G. A. History ofthe Mission of the Evangelical Brethren on the Caribbean Islands of St. Thomas, St. Croix, and St. John. Ann Arbor: Karoma Publishers, 1987.
} 
zonas distintas em relação a esse aspecto. Alguns dos termos que utiliza apontam que se trata de áreas que não são gbe, atualmente situadas em Gana:

Embora a Costa do Ouro não tenha mais que sessenta milhas de extensão, todavia há sete ou oito variadas línguas, tão diferentes que três ou quatro delas são ininteligíveis entre si, a não ser para os respectivos Nativos: os Negros de Junmore, dez milhas acima de Axim, não podem entender aqueles de Egira, Abocroe, Ancobes e Axim. Há de fato uma vasta diferença em suas línguas. Aquela de Axim tem um som brutal e desagradável; a de Ante é bem diferente daquela, embora não muito mais bonita. Mas a mais chocante é a de Acra, que não tem a menor similitude com nenhuma das demais. (BARBOT, 1732, p. 130132, tradução nossa ${ }^{9}$.

Na sequência, ele traça a comparação com outro conjunto de povos, em que haveria intercompreensão:

Os outros Negros da Costa do Ouro, com exceção apenas daqueles de Aquamboe, geralmente entendem-se uns aos outros. Mas os Negros do interior são os mais agradáveis e prazerosos; falo daqueles de Dinkira, Akim, Acanny e Adom; essa diferença é facilmente perceptível, mesmo para uma Pessoa com quase nenhuma familiaridade com suas línguas. (BARBOT, 1732, p. 130 , tradução nossa) ${ }^{10}$.

Barbot (1732, p. 131, tradução nossa"1) ainda aventa a possibilidade de compreender essa língua:

\footnotetext{
9 No original: "Though the Gold Coast is not extended above sixty miles in length, yet we find seven or eight several languages, so different that three or four of them are interchangeably uninteligible to any but the respective Natives: the Negroes of Junmore, ten miles above Axim, can not urderstand those of Egira, Abocroe, Ancobes and Axim. There is indeed a vast difference in their languages. That of Axim is a very disagreeable brutal sound; that of Ante, very different from it, though not much more beautiful. But more shocking is that of Acra, not having the least similitude with any of the rest.".

10 No original: "The other Coast Negroes, those of Aquamboe only excepted, generally understand one another. But the in-land Negroes is by much the pleasantest and most agreeable; I mean those of Dinkira, Akim, Acanny and Adom; this difference is easily discernable to a Person but the least acquainted with their languages [...].".

11 No original: "And if the Negroes, which we dayly converse with, who live about our Forts, expressed themselves as agreeably as the others, 'twould be no difficult matter to learn their Language in two or three years [...] Some of us, amongst which I dare reckon myself, have made such a progress, that we understand the greatest part of it, though we can hardly hit the pronunciation.".
} 
- | O conceito de língua geral de Mina: apontamentos para a compreensão de seu significado histórico

E se os Negros, com quem nós diariamente conversamos, que vivem próximos aos nossos fortes, se expressam tão agradavelmente como os outros, não haveria tanta dificuldade em aprender sua língua em dois ou três anos [...]. Alguns de nós, dentre os quais eu ouso me incluir, têm feito tanto progresso, que nós entendemos a maior parte dessa língua, embora seja muito difícil pronunciá-la.

O traficante francês ainda vai além, apontando que se houvesse uma escrita entre os africanos, ou se os europeus conseguissem transliterar seus "estranhos sons", seria mais fácil dominar a língua:

Pudessem os Negros, como eu dissera, ler ou escrever, nós poderíamos aprender suas línguas rapidamente, observando as Letras que expressam cada coisa; mas não tendo auxílio senão dos sons, eu acho que seria loucura tentar ir além. (BARBOT, 1732, p. 132, tradução nossa'²).

O conceito português de língua geral pode ser entendido nesse quadro da experiência europeia para o estabelecimento das relações comerciais e do tráfico de humanos, diante da diversidade de línguas africanas. Independente de decodificar e construir um conhecimento mais detalhado sobre línguas específicas, tais agentes buscavam esse mapeamento mais genérico de como administrar a diversidade e a comunicação. Daí, listas comparativas, tentativas aproximadas de transliteração, ou avaliações como as pontuadas por Barbot, dentre outros. Ao mesmo tempo, como parte dessa "administração linguística" do tráfico, o uso de intérpretes locais foi decisivo, bem como tentativas de aprendizado ou ao menos compreensão das línguas locais pelos agentes europeus.

Na década de 1720, o reino do Daomé se fortaleceu, conquistando Aladá, Uidá e Jakin. Tanto na invasão do reino de Aladá, em 1724, como na conquista da cidade portuária e reino de Uidá, em 1727, foram feitos milhares de cativos. Comunidades litorâneas foram vítimas desse avanço, como os povos hulas e huedas, que foram nomeados no Brasil como courás ou couranos (MAIA, 2013). O foco de atração principal desse fluxo era justamente a inédita exploração aurífera na América portuguesa. Na década seguinte, a escravização avançou para o interior, atingindo o país mahi, de populações também falantes de gbe. Povos de língua iorubá, chamados anagôs, também foram alvo dessa conquista, estando

12 No original: "Could the Negroes, as I have said, either read or write, we should be able to learn their tongues speedly by observing the Letters which expressed each thing: but having no other assistance than the bare sound, I think 'tis folly to attempt farther". 
presentes, ainda que de forma bem minoritária e pontual nesse período. A preferência dos portugueses por huedas, fons e ardas foi observada em 1728, pela Royal African Company, empresa que organizava o tráfico britânico (SILVA Jr., 2020).

Embora tal demanda não se baseasse apenas na dimensão linguística, havendo também representações apontando um vigor físico dos povos dessa origem, dentre outros aspectos, alguns registros explicitam aquela dimensão, como aponta Carlos Silva. Em documento de 1755, o capitão Jerônimo Leite Ferreira salientou que em Salvador havia grande procura, para as Minas Gerais, de escravizados dos portos de Uidá, Ipé e Popo Grande, "por serem de língua geral"13. A expressão aparece também no relato do traficante escocês Archibald Dalzel, que foi diretor do forte britânico em Uidá, e autor de uma History of Dahomy, do final do século XVIII. Ao apresentar o reino do Daomé, após uma breve introdução geográfica e econômica, afirma:

A língua é aquela que os Portugueses chamam língua geral, e é falada não apenas no Daomé, mas em Uidá, e os outros estados dependentes; e da mesma forma em Mahi, e muitos outros locais vizinhos. (DALZEL, 1967 [1793], p. v, tradução nossa $\left.{ }^{14}\right)$.

Dalzel é portanto um exemplo interessante que associou aos portugueses essa percepção e categorização sobre uma "língua geral", que ele menciona literalmente no seu texto.

Ao optarem por escravos dos grupos étnicos da área gbe, senhores de escravos buscavam não apenas cativos com os quais estavam acostumados a lidar, um resultado direto das zonas de produção de escravos no Golfo do Benim; os documentos acima revelam um interesse direto na obtenção de cativos cujas línguas fossem mutualmente inteligíveis, de alguma maneira associadas à performance econômica no trabalho das minas. Era um cálculo econômico moldando suas preferências e as dinâmicas do tráfico no outro lado do Atlântico. (SILVA Jr., 2020, p. 43-44).

\footnotetext{
13 "Auto da investigação testemunhal a que procedeu o Desembargador António José da Fonseca Lemos", de 20 de março de 1755, AHU, CU, Bahia, CA, doc. 1617. Citado por Silva Jr. (2020).

14 No original: "The language is that which the Portuguese call lingua geral, or general tongue, and is spoken not only in Dahomy-proper, but in Whydah, and the other dependent states; and likewise in Mahee, and several neighbouring places.". O conteúdo do trecho é comentado também por Silva Jr. (2020).
} 
- O conceito de língua geral de Mina: apontamentos para a compreensão de seu significado histórico

Também no espaço americano, o conceito de língua geral através do qual os portugueses apreendiam os povos minas, aparece em registros paroquiais e cartas de alforria. Carlos Silva Jr. apresenta alguns exemplos ocorridos na Bahia, entre 1765 e as primeiras décadas do século XIX ${ }^{15}$. No caso de Vila Rica, foi localizado um registro, feito pelo pároco Pedro Leão de Sá em 1756, em um batismo de 11 escravos do mesmo proprietário: “[...] Batizei [...] a João, a Vitorino, a André, a Domingos, a Bernardo, a Manuel, a Jerônimo, a Tomás, a Pedro e a Matheus, escravos de João Pereira Pinto [...] todos são de nação mina de língua geral". ${ }^{16}$

A noção de uma língua geral entre a comunidade mina foi corrente a ponto de ser utilizada inclusive por um africano liberto mahi (ou maqui) que, após viver em Salvador, se estabeleceu no Rio de Janeiro.

Em 1748 que cheguei a esta Capital vindo da cidade de Bahia, achei já esta Congregação ou Corporação de pretos Minas de varias nações daquela costa a saber Dagomé, Maqui, Iano, Agolin, Sabaru, todos de língua geral com muita união. [...] e continuando o tempo começaram os pretos a se zingarem as Nações umas com as outras [... $]^{17}$..

Sua experiência apontou exatamente uma possibilidade de comunicação entre nações que se entendiam como distintas entre si. Com exceção do etnônimo lano, cuja identificação não está estabelecida, os demais referem-se a povos falantes de gbe. Esse curto testemunho ganha uma importância preciosa para a compreensão de que havia uma língua partilhada, que permitiu uma associação, mas não anulava os sentimentos de identidades particulares.

\section{O conceito gbe}

Passemos agora a buscar a experiência linguística da região, em uma perspectiva endógena, construída por dois pesquisadores e linguistas beninenses: Hounkpati Capo (1983, 1988, 1991), autor que se dedicou à difusão e definição do conceito de gbe, e

15 Dentre outros exemplos citados pelo autor, há esse: “Óbito de João, da Costa da Mina, língua geral”, de 19 de janeiro de 1765, ASCMBa, Livro de Registro de Banguê 1261 (1764-1772), f. 24. (SILVA Jr., 2020, p. 44-45).

16 Arquivo Eclesiástico de Nossa Senhora do Pilar de Ouro Preto. códice 493, fl.135v, Registro de Batismo de 25/07/1756. Uma parte desse registro foi citada por Maia (2013) a quem devo a localização do documento.

17 Estatutos da Congregação dos pretos minas Maki no Rio de Janeiro (1786). Biblioteca Nacional, seção de Manuscritos, 9, 3, 11. Soares (2019) organizou uma edição do documento, acompanhada de um estudo histórico. 
Christian Hounnouvi (2020), que apresenta algumas ponderações bastante ricas à difundida teorização de Capo, e ensaia uma interpretação sobre a obra de Antônio da Costa Peixoto e sobre o significado múltiplo do termo mina.

Precisamos antes nos despir de algumas visões naturalizadas que apontam fronteiras linguísticas construídas pela história ocidental que associam uma língua a uma nação. A formação dos estados nacionais, em um processo longo, mas que se consolidou no século XIX, teve como um de seus elementos de construção da soberania a definição de línguas nacionais que subsumiu um quadro de diversidade linguística interna. A partir da escolarização, da unificação da língua escrita, da produção de uma administração centralizada, dentre outros processos, esvaziou regionalismos, variedades linguísticas, particularidades locais, forjando a noção de uma língua única que se decalcaria das fronteiras políticas nacionais, de onde emanou um nome para tais línguas unificadas: $\mathrm{o}$ inglês, o francês, o português, o espanhol, o italiano ${ }^{18}$... Assim, despidos dessas visões, sabemos que a diversidade linguística é intrínseca ao uso da linguagem. E ainda que o multilinguismo, ou a faculdade de se comunicar em outras línguas, é algo também intrínseco, embora essa mesma faculdade tenha sido e continue sendo coibida pelas políticas linguísticas unificadoras de estados nacionais. No continente africano, além da diversidade linguística estimada em cerca de 2 mil línguas, ou um terço das línguas do globo (estimado em 6 mil línguas vivas no início do século XXI), o multilinguismo faz parte da experiência cotidiana dos povos (BONVINI; BUSUTIL; PEYRAUBE, 2011, capítulo "Les langues d'Afrique").

Essa última noção ajuda a que deixemos de lado outra visão distorcida, composta pelo imaginário de que a diversidade linguística africana levaria a uma incomunicabilidade. Imaginário construído externamente, que por vezes é reificado pela historiografia sobre a escravidão no Brasil (LIMA, 2017).

Como definiu Hounkpati Capo, no Golfo do Benim, em uma área geográfica que se estende do curso inferior do rio Volta (ou Amugan) a oeste, ao rio Ouémé/Wemé (ou Wógbó) a leste, e do litoral atlântico ao sul, até a latitude $9^{\circ}$ ao norte, área que atravessa os países do Gana, Togo, Benim e Nigéria, por volta de 50 línguas aí faladas poderiam ser reunidas no grupo gbe (CAPO, 1991) ${ }^{19}$. Teria existido um proto-idioma do qual esse

18 No campo da história, diferentes autores se dedicaram a analisar esse processo. Sobre o conceito de comunidades imaginadas, e a importância da língua impressa e unificada para a formação da nação, ver Anderson (1999). Sobre a política da Revolução Francesa acerca da diversidade linguística, ver a obra coletiva de Certeau, Julia e Revel (1975). O caso italiano e as discussões teóricas são feitas ainda por Steinberg (1997).

19 O consenso sobre o uso do termo gbe foi resultado de discussões no $14^{\circ}$ Congresso de Línguas Africanas, que ocorreu em Cotonu, Benim, em 1980 (CAPO, 1991). 
- | O conceito de língua geral de Mina: apontamentos para a compreensão de seu significado histórico

complexo seria formado, embora essa hipótese não tenha sido demonstrada com clareza (HOUNNOUVI, 2020). As línguas gbe são classificadas como línguas cuá (kwa), que por sua vez fazem parte do tronco nígero-congolês. Vizinhas, línguas de outras famílias são faladas nas regiões fronteiriças: iorubá, adele, akpafu, acan, dangme. E dentro da área gbe haveria enclaves de falantes de avatime, lolobi e aguna (CAPO, 1988).

Capo propõe que essas cerca de 50 línguas podem ser identificadas em um continuum linguístico, ou complexo dialetal, ou mesmo como uma língua única, devido ao grau de intercompreensão entre si, que pode ser maior ou menor dependendo das línguas envolvidas. Ao mesmo tempo, o autor reconhece e não pretende invalidar os sentimentos comunitários, os contornos étnicos e as especificidades linguísticas que envolvem cada um desses falares. O autor classifica essas 50 línguas em 5 grupos: vhe (ou ewe), gen, aja, fon e phlá-pherá. Ao mesmo tempo em que, dentre esses povos, existiriam diferenças de cunho linguístico, simbólico, político, haveria um continuum. Assim, ainda que considerando tais especificidades, na perspectiva dos seus distintos grupos, o linguista propõe que se forje, na língua escrita, uma estandartização que serviria ao conjunto desses povos. A escolha pelo termo gbe, que significa língua em todas essas variantes, foi justificada por ser um termo neutro, que superaria a disputa envolvida em escolher um dos nomes específicos, como fon ou ewe para orientar esse projeto. A questão que estaria em aberto seria justamente saber se é possível falar em uma língua gbe, no singular, ou em um aglomerado (cluster) de línguas ${ }^{20}$.

O conceito de gbe é útil também para perceber criticamente a história dos instrumentos linguísticos (AUROUX, 2009) produzidos pelo colonialismo europeu dos séculos XIX e XX, que disseminaram nomeações próprias e usaram sistemas de transcrição fonética específicos. Como aponta Capo, na tradição alemã, seguida pelos autores de língua inglesa, o termo ewe se tornou comum, a partir da obra de Schlegel, Schlüssel zur Ewe-Sprache, de 1857 e Alfred B. Ellis, The Ewe-Speaking Peoples of the Slave Coast of WestAfrica, de 1890. Os franceses, que tenderam a usar mais o conceito de aja, adja, ou adja-fon, usaram também a nomenclatura "daomeano", como aponta a obra de Maurice Delafosse,

20 “On vient de montrer, ou d'argumenter que, quelque soit la definition de 'langue' par rapport à 'dialecte' e a 'groupe de langues', tout le continuum Gbe peut être traité - en fait devrait être traité - comme une seule langue. Convaincu que cette position est à l'avantage des populations locutrices de cette langue, ainsi que de l'unité africaine, j'ai ainsi insinué qu'il est possible d'avoir une orthographe standard du Gbe. Je dois dire maintenant, de façon explicite, qu'il faut s'engager dans la voie de la standardisation consciente du Gbe pour en faire une langue moderne et sous-régionale." (CAPO, 1983, p. 55). Em texto posterior, de 1988, provavelmente pelas críticas recebidas, o autor reforçou a questão das singularidades existentes, das representações particulares dos povos envolvidos sobre suas marcas linguísticas. Em texto de 1991, ele afirma que a questão de se tratar de uma língua única ou de um cluster continuaria em aberto e discute, dentre outros pontos, o nome que os próprios falantes atribuiriam a suas línguas. 
Manuel Dahoméen, de 1894 e de missionários católicos como o padre Basilio Segurola, que começou a elaborar seu dicionário fon-francês em 1948. Capo enumera e analisa toda uma tradição escrita sobre as línguas gbe, apontando a heterogeneidade dos critérios de transcrição, que em geral obedeciam ao próprio alfabeto das línguas europeias dos seus autores. Mesmo as tentativas de transcrição com sistemas padronizados seriam ainda limitadas. Essa situação impediria trocas mais amplas na língua escrita. Um dos objetivos de Capo seria exatamente definir critérios para uma estandartização de uma escrita que pudesse atender à proposta de unificação, bem como alçar o gbe a uma "modernização" (CAPO, 1988, p. 47).

O pesquisador beninense Christian Hounnouvi traz uma abordagem bem interessante, pois considera a diáspora mina em uma perspectiva africana e endógena, e discute criticamente as posições colocadas por Hounkpati Capo na década de 1980, buscando por um lado relativizar a intercompreensão e, por outro, frisar o multilinguismo da experiência gbe. Na medida em que, na diáspora, eram englobados na categoria mina tanto povos do litoral, como do interior, Hounnouvi (2020, p. 64) afirma que "Embora até certo ponto pudessem se entender, eles falavam idiomas diferentes".

A classificação mais aceita das línguas gbe é a do professor Hounkpati Capo, que as divide em cinco grupos de dialetos vhe (ou ewe), gen, ajá, fon e phlapherá (xwla-xweda). Mas essa classificação não deve obscurecer o mosaico impressionante que o mapa linguístico gbe realmente é. Só no Benim, esses grupos costumam ser divididos em uma dúzia de subgrupos que, por sua vez, são compostos por uma infinidade de topoletos mais ou menos diferentes. Para cada topoleto, o número de falantes pode variar de algumas centenas a alguns milhares, e nem sempre é fácil enumerá-los e agrupá-los. A esta divisão válida no Benim, os subgrupos ganenses e togoleses devem ser adicionados para obter uma visão mais completa deste continuum dialetal. (HOUNNOUVI, 2020, p. 67).

Hounnouvi apresenta o que entende pela situação de intercompreensão, tanto na área gbe, como provavelmente também na diáspora dos gbe-falantes: os interlocutores falam, cada um, sua própria língua e assim estabelecem a comunicação. No entanto, há exemplos em que essa intercompreensão não ocorre, como no caso dos falantes de xwla do sul do Benim, que não compreenderiam as línguas aja e ewe, sendo necessário o recurso a uma língua franca (gen ou gun). Haveria situações em que o bilinguismo precisaria ser acionado para se estabelecer a comunicação, pois além de diferenças lexicais, haveria distanciamentos nos verbos e estruturas sintáticas (HOUNNOUVI, 2020). 
- | O conceito de língua geral de Mina: apontamentos para a compreensão de seu significado histórico

Outra contribuição importante de Hounnouvi diz respeito à existência de uma língua franca na área gbe: o gengbe. Segundo já havia sido apontado por Capo, o gengbe funcionaria como uma espécie de eixo do continuum gbe.

Com efeito, seja devido à influência generalizada do reino que o consolidou, seja porque muitos mercadores beninenses se abasteciam com produtos de todos os tipos no sul do Togo já no século XIX, ou ainda porque se tratava de uma língua com uma morfossintaxe mais acessível, o gengbè foi e continua a ser a única língua veicular cuja extensão cobre toda a costa, desde o oeste de Lomé até a região de Cotonu, incluindo o Mono mais ao norte. (HOUNNOUVI, 2020, p. 75).

Haveria indícios de que, em meados do século XIX, essa língua já fosse utilizada para essa intercomunicação, o que apontaria que sua formação deve ter se dado ainda antes desse período. A língua gen seria também chamada, por alguns, de mina. Seria tanto uma língua materna como uma língua para trocas comerciais e administrativas, uma língua de comunicação.

No Benim, o lexema mina refere-se a uma língua materna, ou segunda língua, de povos do sudoeste do país, principalmente os habitantes da região do Mono. Seu uso é quase exclusivo em cidades como Agoue ou Hilacondji, onde a influência Gen se fez presente desde o século XVIII. É a língua de identificação de muitos falantes desta região e serve como língua de comunicação em múltiplos contextos, inclusive sendo considerada uma língua nacional. (HOUNNOUVI, 2020, p. 62).

Os gen são povos que migraram de Accra para Anexo no século XVII e é nessa área que estão estabelecidos, com influência até o Popo Grande.

É falado em toda a capital e seus arredores como uma língua franca. Podemos ver então, do prisma endógeno benino-togolês, como os etnônimos gen e mina referem-se a uma realidade cultural e a um contexto geográfico bem definido. Diversos autores, entre os quais o ganês Divine Edem Kobla Amenumey, apresentam-nos os motivos dessa pluralidade de denominações, além de confirmarem a visão exógena que o termo mina carrega e o caráter local do etnônimo gen. (HOUNNOUVI, 2020, p. 63). 
Numa análise preliminar da Obra nova da língua geraldeMina, Hounnouvi identificou traços de quatro línguas, que ocorrem nos atuais países Benim e Togo: kogbè (cotafon) (na área de fronteira com o Togo), fongbè (na parte central sul do Benim), gungbè (leste), géngbè (Togo e parte ocidental do Benim).

Após a primeira leitura que fizemos do manuscrito de língua geral de Peixoto, notamos uma morfossintaxe e um léxico que tendem a um predomínio de palavras e estruturas cotafon / fon. A língua gun, também presente, era menos representada; notamos uma tímida presença do gengbè, e o ewe ganense era quase ausente. (HOUNNOUVI, 2020, p. 75).

Isso leva o autor a se perguntar por que o manuscrito de Peixoto não manifestou a existência dessa língua franca já existente entre os povos gbe, e sim, predominantemente, o fon/cotafon. A língua chamada mina, da região da área gbe do Togo e parte do Benim, denominada preferencialmente por esses falantes como gengbe, em nada corresponde, portanto, ao que os portugueses denominaram língua geral de Mina, ao menos tal como foi registrada por Peixoto.

\section{A Obra nova da língua geral de Mina}

O histórico do conhecimento linguístico dos séculos XIX e XX sobre as línguas gbe apresentado por Capo, acrescentado dos registros dos séculos XVII e XVIII elencados e brevemente discutidos na primeira parte desse artigo, evidencia a dimensão temporal e a especificidade do conceito setecentista português: diante das diversidades ${ }^{21}$, não projetavam na ideia de língua geral exatamente uma unidade, mas antes a possibilidade de comunicação. Essa dimensão histórica sobre os registros e representações acerca dos povos gbe permite também situar a especificidade da Obra nova da língua geral de Mina. Não é nossa intenção, nesse artigo, fazer uma análise ampla dessa obra, e sim dialogar com alguns aspectos já comentados por outros pesquisadores, remetendo a trabalhos já publicados (LIMA, 2018, 2020).

Antonio da Costa Peixoto foi escrivão e juiz da vintena, cargos inferiores da administração colonial, tendo morrido pobre e solteiro (ARAÚJO, 2013). Peixoto não tinha uma formação intelectual específica como aquela a que os missionários religiosos

21 No início da década de 2000, os estudos historiográficos sobre culturas africanas no Brasil tiveram um grande desenvolvimento, motivado, dentre outros fatores, pela lei de 10.639/2003. A essa altura, Silvia Lara (2002) publicou um artigo no qual aponta a percepção das etnicidades africanas, pelos próprios agentes escravistas e a relação entre a linguagem e o domínio senhorial. 
- | O conceito de língua geral de Mina: apontamentos para a compreensão de seu significado histórico

tiveram acesso para construir todo um mapeamento linguístico dos povos que buscaram doutrinar. Por outro lado, ele conseguiu forjar um sistema de transcrição para a língua mina. Aproximou convenções alfabéticas da língua portuguesa para enfrentar sonoridades distintas e criar um critério para transformar aquilo que ouvia em escrita e organizar o vocabulário. Boa parte do documento foi construído com pequenos "blocos" de textos, à maneira de parágrafos, organizados por campos semânticos e por associação temática, e não por ordem alfabética. Aos termos na língua mina se seguem os termos em português. Seu formato é semelhante a listas de palavras, registros comuns quando se tratou de decodificar a língua do outro, elaboradas por viajantes, exploradores, comerciantes, que buscavam um uso prático. Tais blocos semânticos, ou de associação temática, se seguem em boa parte do vocabulário: corpo, vestimentas, utensílios, comidas, animais de criação, atividades ligadas ao trabalho, etc. Além de palavras, de vez em quando pequenas frases são inseridas. Como em "zo-fogo//zoqui - apagou-se o fogo//zotim = tem fogo" ou zemmárófihéháhâ, "a panela ainda não ferve", hiháhúfelázou nim, "sopra-lhe o fogo depressa". A determinada altura (f. 6 do manuscrito de 1731, f. 14 no de 1741) além de frases, perguntas e diálogos, aparecem algumas vezes introduzidos com os marcadores "Pergunto" e "Responde". Os diálogos e traduções apresentados por Costa Peixoto, em seu contato com os falantes de língua mina, representam relações sociais na escravidão. Tratase de um peça textual que, para além do que tenham sido seus objetivos e formas de uso e circulação, opera uma representação e uma elaboração simbólica sobre a experiência. Daí a potência dos diálogos relacionados à violência brutal e à tensa negociação da escravidão (ver a esse respeito o estudo de Lara, 2002), com um teor dramático raríssimas vezes explicitado.

Aryon Rodrigues (2002) nos brinda com uma belíssima história sobre como conheceu o "livrinho de Costa Peixoto" e o que fez com ele. Em 1957, pesquisava nos arquivos portugueses, em uma missão da Universidade de Hamburgo sobre línguas africanas, onde conheceu Luís da Silveira que, em 1944, quando dirigia a Biblioteca Pública de Évora, fora o responsável pela primeira publicação impressa do manuscrito de 1741. Aryon conta que essa edição foi censurada e apreendida pelo governo salazarista. Já no ano seguinte, Silveira fez uma nova edição, dessa vez incorporando as informações do manuscrito de 1731, do acervo da Biblioteca Nacional de Lisboa. Essa edição de 1945 tentou se ajustar ainda mais à censura, expurgando trechos em português (o que já tinha intentado fazer na primeira edição, mas não foi suficiente para ajustar a "licenciosidade" condenada pelos valores da época). Minha hipótese é que o motivo da restrição à circulação e consulta da obra foi a forma como a violência da escravidão aparece ali representada, bem 
como a possibilidade de uma negociação e resistência da parte dos escravizados ${ }^{22}$. Os africanos falantes de mina são representados na obra como enunciadores, interlocutores de um diálogo com o mundo que os escravizou (LIMA, 2018, 2020), e isso seria talvez insuportável para o regime colonialista e ditatorial português.

Aryon conta que, após obter autorização para adquirir um exemplar na Agência Geral das Colônias (órgão do governo que lidava com a administração das colônias africanas e que havia editado o livro), teve oportunidade de cotejar a edição impressa com o manuscrito em Évora, com uma interessante síntese,

[...] tendo anotado à margem de meu exemplar desta todas as divergências que encontrei devidas a leituras equivocadas ou a descuidos de quem executou a cópia para a publicação. A grande maioria das diferenças tem a ver com a leitura dos acentos gráficos, mas também houve omissão acidental de algumas poucas frases e a omissão proposital - imposta pela censura - de muitas traduções. (RODRIGUES, 2003, p. 92).

Dedicando-se depois a seus estudos sobre a língua tupinambá, tendo se tornado um dos principais especialistas sobre línguas indígenas, só voltou ao trabalho de Peixoto nos anos de 1980, quando fez amigos beninenses que estudavam na UNICAMP, sendo dois que falavam o fon, um falante de gun, e outro de mahi. Com esses amigos, de forma mais sistemática com um dos falantes de fon, leu a escrita de Peixoto e de certa forma re-oralizou todo o documento, partindo do que estava escrito a uma nova transcrição fonética e chegando a uma contundente conclusão:

Pelo menos 90\% dos dados do manual de Costa Peixoto foram imediatamente reconhecíveis, não só os vocábulos soltos, mas igualmente as sentenças, de modo a não deixar dúvidas de que a língua em questão pertence ao complexo dialetal Ewe [Gbe] e coincide sobretudo com o Fõ. Algumas formas divergem e se identificam com um ou outro dialeto, ora com o Mahi, ora com o Gum. (RODRIGUES, 2003, p. 93).

Nessa espécie de performance, Aryon Rodrigues e os estudantes beninenses, ao emprestarem uma forma oral à escrita de Peixoto, injetam vida naquele documento,

22 Em 2018, consultei diferentes acervos portugueses em busca de registros sobre a censura e limitações à circulação das edições de 1944 e 1945 da Obra nova da língua geral de Mina, mas infelizmente não consegui localizar tais informações. Ao menos àquela altura, a documentação da Agência Geral das Colônias, sob a guarda do Arquivo Histórico Ultramarino, não estava organizada. Buscas nos diários oficiais e outros arquivos foram também infrutíferas. 
- | O conceito de língua geral de Mina: apontamentos para a compreensão de seu significado histórico

sendo a melhor evidência de que se tratava ali de um registro íntegro de uma comunicação africana na primeira metade do século XVIII. Rodrigues adverte também que dada a proximidade fonológica, gramatical e lexical dessas línguas, a correspondência exata com a chamada língua mina nas Gerais seria uma tarefa difícil, mas que a proximidade com o fon e o gun seriam as mais percebidas.

Outra pesquisadora brasileira construiu com a obra de Antonio da Costa Peixoto uma aventura de conhecimento também muito instigante. A etnolinguista Yeda Pessoa da Castro fez um trabalho de campo entre 1972 e 1974 nas cidades de Porto Novo e Abomey, no Benim, com o interesse principal de cotejar o vocabulário recolhido em terreiros de candomblé da Bahia, bem como o registro de Peixoto, para melhor compreender o que ela denominou como língua mina-jeje no Brasil. Ela organizou uma nova edição do documento, emprestando a ele uma ordenação bem diferente, listando as entradas em ordem alfabética (o documento original foi organizado, em geral, por associação conceitual). $82 \%$ do vocabulário foi identificado por ela como correspondente à língua fon, sendo o restante identificado como mina (outro nome para a língua gen), gun, ewe e mahi (CASTRO, 2002) ${ }^{23}$. Ao lado de cada entrada, apontou o correspondente da transcrição fonética do fon, algo que Aryon Rodrigues também havia feito no seu material de trabalho que permanece inédito. Dessa forma, a edição publicada por Castro é uma ferramenta muito útil para conhecer e explorar a Obra nova, embora tenha acabado por suprimir muito do que a estrutura original do documento indica e sugere. $\mathrm{O}$ volume buscou também uma interpretação histórica e cultural dos elementos do vocabulário.

Wellington Santos da Silva (2020), a partir de uma minuciosa análise inspirada no trabalho do linguista beninense Enoch $\mathrm{O}$. Aboh, indica que a língua geral de Mina tal como documentada por Antonio da Costa Peixoto, seria fruto da situação diaspórica do encontro de falantes de línguas gbe, com inovações na sua estrutura sintática. Seu trabalho reitera que o registro feito na Obra nova foi bem-sucedido no sentido de ter apontado uma língua plena, no entanto se distingue de trabalhos anteriores por focalizar a morfossintaxe da língua registrada. Silva (2020, p. 209) identificou na língua geral de Mina características de uma "gramática essencialmente gbe", principalmente do grupo oriental, fongbe e gungbe, embora com inovações devidas à ecologia das línguas naquele contexto específico, que pôs em comunicação falantes dos distintos grupos gbe, falantes de português e africanos de outras áreas. Com os dados que apresenta, ele embaralha outras análises, mais centradas na conferência do léxico, que apontaram o predomínio fon, para mostrar que há elementos morfossintáticos também do gun, embora esses tenham

$23 \mathrm{Na}$ tabela em que classifica os itens lexicais do documento, a autora não menciona mais o gen (mina), ver Castro (2002). 
sido reconfigurados em formas de falar inovadoras da diáspora. Deixando de lado noções correntes de que houve uma "perda" ou "degeneração", sua análise reitera a vitalidade e uma capacidade de negociar a comunicação. Essa dimensão é bastante interessante, quando investigamos como os povos africanos escravizados e traficados reconstruíram seus vínculos sociais e comunitários.

Uma marca interessante de tais pesquisas é a colaboração com falantes beninenses do gbe. O professor Aryon Rodrigues com os jovens estudantes, Yeda Pessoa de Castro com seu trabalho de campo, Wellington de Souza com o linguista Enoch O. Aboh. Nossa aposta é que também Antonio da Costa Peixoto contou com a colaboração anônima dos falantes da língua mina, os quais podem ser considerados de alguma forma coautores do vocabulário (YAY, 2000; LIMA, 2018 e 2020). Quando esse documento é lido à luz da historiografia sobre os povos categorizados como minas, ou categorias subjacentes (couranos, mahis, jejes, savalus, ladanos, dagomés e outras) em diferentes partes do Brasil, e mais particularmente nos estudos sobre a área mineradora onde veio à luz o registro de Costa Peixoto, é bastante visível a perspectiva africana que o moldou. A experiência feminina nas relações de comércio, nas questões de intimidade e vida afetiva, nos usos e apropriações da própria língua senhorial pode ser acompanhada na leitura cruzada do documento com outras fontes e trabalhos analíticos. As análises linguísticas aqui referidas, de Rodrigues, Castro e Wellington, são bastante pertinentes face ao conhecimento demográfico sobre o tráfico para a então América Portuguesa que, no século XVIII, teve um amplo predomínio de povos falantes de línguas gbe (SILVA Jr., 2020; PARÈS, 2007, MAIA, 2013, dentre outros).

Como conciliar, porém, o meu argumento de que "língua geral de Mina", nas suas ocorrências genéricas, significaria antes uma representação portuguesa sobre a possibilidade de comunicação, com o registro feito por Antonio da Costa Peixoto, cujas análises linguísticas apontam para o predomínio do fon (HOUNNOUVI, 2020; RODRIGUES, 2003; CASTRO, 2002), ou para uma variante inovadora com traços do fon e gun (SILVA, 2020)?

\section{Conclusão}

Para construir a ordem colonial e escravista, o conceito (político e intelectual) de língua geral foi estratégico. Na relação com os povos ameríndios, o uso do conceito é bastante conhecido. Ocorreu também na relação com os povos da região Congo- 
- | O conceito de língua geral de Mina: apontamentos para a compreensão de seu significado histórico

Angola ${ }^{24}$. Até onde já consegui perceber, é uma expressão que foi corrente entre as línguas ibéricas. "General language" não é uma expressão utilizada em inglês, por exemplo, sendo mais corrente a noção de língua franca. Ao menos no significado aqui apontado, língua geral, no universo cultural português, em seu uso histórico no período colonial, não significaria exatamente o mesmo que língua franca. Foi empregado como uma forma de administrar a diversidade de línguas e povos a serem incorporados e submetidos a essa ordem. Estabelecer a comunicação, mapear as línguas faladas, construir conhecimento e instrumentos de domínio sobre as mesmas (vocabulários, dicionários, gramáticas, catecismos), fez parte da colonização linguística, que de alguma forma arruma o cenário para a difusão da língua do colonizador, que foi lenta e violenta. Línguas gerais são, nesse sentido uma categoria conceitual política talvez inventada pelos portugueses. Inventada, ou forjada, sobre uma prática de intercomunicação vivenciada pelas habilidades linguísticas dos povos envolvidos. O fato de ser um constructo político e cognitivo é importante para que não deduzamos, numa projeção, que as práticas linguísticas na Costa da Mina correspondiam à existência de uma língua. Ou que sua comunicação dependesse especificamente dessa uma língua comum, projetada de forma exógena. $\mathrm{O}$ ambiente cotidiano desses povos era marcado pelo multilinguismo.

É possível que o conceito de língua geral empregado para os povos da Costa da Mina seja decorrente da experiência colonizadora ibérica com os povos ameríndios, e portanto é interessante um contraponto sobre sua aplicação no quadro americano e no africano. No caso das línguas gerais indígenas, há muito mais registros históricos e uma maior tradição de pesquisas na área dos estudos linguísticos. Produções da historiografia linguística associam o conceito a uma política linguística ibérica, como por exemplo a coletânea e seminário sobre o tema, realizado na UERJ em 200025: "políticas de difusão de algumas línguas ameríndias, identificadas pelos colonizadores como 'línguas gerais', em face da extensão e posição de seus falantes, bem como pelas funções que elas desempenham." (ROSA; BESSA-FREIRE, 2003, p. 7). Mais especificamente, se tratou de uma política missionária, estimulada pelas monarquias, que visaram atender ao projeto de catequese, e consequentemente ao estabelecimento de uma ordem colonial específica. A proposta de obter uma comunicação com povos distintos em uma língua mais ou menos uniforme, contou, por um lado, com características linguísticas dos povos indígenas envolvidos nas diferentes situações - vide, por exemplo, a percepção sobre a "língua mais falada na costa", cristalizada no trabalho de José de Anchieta, ou a existência de uma koiné

24 Cannecatim, missionário que atuava em Angola desde as últimas décadas do século XVIII, trata da "Língua Bunda, ou geral do Reino de Angola" (CANNECATIM, 1804, p. iv).

25 I Colóquio sobre Línguas Gerais: Política Linguística e Catequese na América do Sul no Período Colonial. 
no império Inca, como mostra Consuelo Alfaro Lagorio, preexistente à invasão ibérica e que serviu de base a uma tentativa de expansão padronizada pelos agentes coloniais (LAGÓRIO, 2003). Mas por outro lado, para que tal política ganhasse consistência, todo o trabalho de decodificação escrita dessa "língua geral" foi fundamental para que a mesma atingisse certo grau de uniformização e circulação. Assim, o fenômeno de sua formação não se separa da elaboração de vocabulários, descrições gramaticais, catecismos. Havia ainda um empenho explícito para que padres e catequistas aprendessem tais línguas. Os colégios jesuítas da América Portuguesa foram espaços dessa formação missionária. Houve assim um efeito importante em que esse processo de decodificação, circulação dos instrumentos linguísticos e aprendizagem, em meio a falantes "não nativos", e novos usos e funções sociais, teria levado a mudanças estruturais (RODRIGUES, 1996). BessaFreire (2007) descreve e analisa a implantação da língua geral amazônica entre povos não tupis no Rio Negro.

Mas o caso da língua geral de Mina, ao menos com a documentação e referências que puderam ser utilizadas, parece ter sido bem diferente. Insistimos aqui na hipótese de uma possibilidade de comunicação entre falantes de línguas próximas (ou muito próximas), mais do que na identificação de uma língua específica compartilhada, pois não houve (ou não restaram indícios) de nenhuma produção escrita de instrumentos linguísticos para o que chamaram de língua mina, da forma como houve para as línguas ameríndias, de forma a ocasionar ou mesmo produzir um uso mais ampliado e relativamente mais homogêneo. Considero improvável que a Obra nova tenha circulado muito além do entorno de Vila Rica, embora seu formato e a frase final do autor sugiram a possibilidade de cópias manuscritas, indícios de que teve uma circulação local. Seu conteúdo, porém, estaria muito longe de ser aceito em uma sociedade de códigos morais rígidos.

Tenho dado fim ao que prometi, no princípio deste caderno; e peço ao dono dele, o estude, de sorte que dê por bem empregado o limitado dispêndio. $E$ que o não empreste, nem traslade, nem dê a trasladar a ninguém, e finalmente me enculque curiosos para que me comprem outros volumes, que com ânsia e fervor, fico dando ao prelo, e breve me sairão. E do contrário me darei por muito mal servido; e satisfeito pois notório e público a grande despesa, e esplêndido gasto que tenho feito, nesta nova oficina. (PEIXOTO, 1741, fólios 41 e 42).

Dessa forma, para além de identificar a que línguas específicas a chamada língua mina poderia corresponder, vale não perder de vista que havia diferentes povos que conseguiam se comunicar uns com os outros. 
- | O conceito de língua geral de Mina: apontamentos para a compreensão de seu significado histórico

Deve-se assim considerar que o trabalho de Peixoto nunca será representativo de toda a comunicação estabelecida pelos gbe falantes entre si e com os falantes de português (e quem sabe de outras línguas) nas Minas Gerais nas primeiras décadas do século XVIII. Isto é, que a comunicação travada entre os povos falantes de línguas atualmente classificadas como gbe, foi sem dúvida muito mais amplo do que o registro fixou. Em outras áreas da América, outras soluções podem ter sido elaboradas pelos povos gbe para sua intercomunicação. Na Bahia, onde se formou uma "nação jeje" metaétnica entre falantes de gbe, nos termos apontados por Nicolau Parès (2007), devem ter surgido outras soluções e negociações. Da mesma forma, no Rio de Janeiro setecentista, a percepção de uma língua geral da nação mina (SOARES, 2002, 2019) pode ter tido características distintas. Os falantes africanos, classificados pelos portugueses como mina ou como "de língua geral mina" (ou jeje, no caso baiano), que usavam línguas gbe, já se comunicavam na sua terra e suas conversas certamente foram além do que foi denominado e registrado como a língua geral de Mina.

\section{Agradecimentos}

Agradeço ao CNPq pela bolsa de produtividade (PQ2), aos bolsistas PIBIC Ana Luíza Guimarães Ribeiro, Lucas Sampaio Costa Souza e Vinicius Steidle, e aos diferentes interlocutores da área de Linguística que contribuíram para essa abordagem transdisciplinar, particularmente aos colegas do Laboratório de Estudos Linguísticos Transatlânticos (USP). Agradeço ainda as sugestões e críticas dos pareceristas anônimos.

\section{Referências}

$\mathrm{ABOH}, \mathrm{E}$. O. The Emergence of Hybrid Grammars. Language Contact and Change. Cambridge: Cambridge University Press, 2015.

ANDERSON, B. Nação e consciência nacional. São Paulo: Ática, 1989.

ARAÚJO, F. Fome de ouro e fama da obra. Antonio Costa Peixoto e a Obra Nova de Lingoa Geral Mina. 2013. Disponível em: http://www.antropologia.com.br/arti/colab/ a53-faraujo.pdf. Acesso em: 20 abr. 2014.

AUROUX, S. A revolução tecnológica da gramatização. Campinas: Editora UNICAMP, 2009.

BARBOT, J. Description of the Coasts of North and South Guinea. s. ed.: Londres, 1732. Disponível em: https://archive.org/details/b30453549. Acesso em: 24 nov. 2021. 
BESSA-FREIRE, J. R. B.; ROSA, M. C. Línguas Gerais. Política lingüística e catequese na América do Sul no período colonial. Rio de Janeiro: EdUERJ, 2003.

BONVINI, E.; BUSUTIL, J.; PEYRAUBE, A. Dictionnaire des langues. Paris: PUF, 2011.

CANNECATIM, B. Diccionario da Lingua Bunda, ou Angolense, explicada na portuguesa, e latina. Lisboa: Impressão Régia, 1804.

CAPO, H. B. A Comparative Phonology of Gbe. Berlin: De Gruyter Mouton, 1991.

CAPO, H. Renaissance du Gbe: réflexions critiques et constructives sur l'eve, le fon, le gen, l'aja, le gun etc. Hamburg: Helmut Buske Verlag, 1988.

CAPO, H. Le Gbe est une langue unique. Africa: Journal of the International African Institute, v. 53, n. 2, p. 47-57, 1983.

CASTRO, Y. P. de. A língua mina-jeje no Brasil: um falar africano em Ouro Preto do século XVIII. Belo Horizonte: Fundação João Pinheiro, 2002.

CERTEAU, M. de; JULIA, D.; REVEL, J. Une politique de la langue. La Révolution Française et les patois: I'enquête de Grégoire. Paris: Gallimard, 1975.

DALZEL, A. The History of Dahomy, an Inland Kingdom of Africa [1793]. Londres: Frank and Cass, 1967. Disponível em: https://archive.org/details/b28764808. Acesso em: 24 nov. 2021.

HOUNNOUVI, C. Povos gbe da Costa da Mina: questionando a intercompreensão e a identidade linguística. In: RODRIGUES, A.; FARIAS, J.; LIMA, I. S. (org.). A diáspora mina: africanos entre o golfo do Benim e o Brasil. Rio de Janeiro: Nau Editora, 2020. p. 55-83.

KLUGE, A. The Gbe Language Continuum of West Africa: A Synchronic Typological Approach to Prioritizing In-Depth Sociolinguistic Research on Literature Extensibility. Language, Documentation and Conservation, v. 1, n. 2, p. 182-215, dez. 2007.

LABAT, J.-B. Voyage du Chevalier des Marchais em Guinée, isles voisines et à Cayenne, fait em 1725, 1726 et 1727, Tomo 4. Paris: Saugrain, 1730. Disponível em: https:/ / archive. org/details/LabatMarchais1731. Acesso em: 24 nov. 2021. 
- | O conceito de língua geral de Mina: apontamentos para a compreensão de seu significado histórico

LAGÓRIO, C. A. Elementos de política linguística colonial hispânica: o Terceiro Concílio Limense. In: BESSA-FREIRE, J. R.; ROSA, M. C. (org.). Política linguística e catequese na América do Sul no período colonial. Rio de Janeiro: EdUERJ, 2003. p. 43-57.

LARA, S. Linguagem, domínio senhorial e identidade étnica nas Minas Gerais de meados do século XVIII. In: ALMEIDA, M. V. de; BASTOS, C.; FELDMAN BIANCI, B. (org.).

Trânsitos Coloniais. Lisboa: Imprensa de Ciências Sociais, 2002. p. 205-225.

LAW, R. Jean Barbot as a Source for the Slave Coast of West Africa. History in Africa, v. 9, p. 155-173, 1992.

LEITE, S. História da Companhia de Jesus no Brasil. Tomo VIII. Rio de Janeiro/Lisboa: Civilização Brasileira/Portugália, 1949.

LIMA, I. S. Tradução mina para a terra do branco. In: RODRIGUES, A.; FARIAS, J.; LIMA, I. S. (org.). A diáspora mina: africanos entre o Golfo do Benim e o Brasil. Rio de Janeiro: FAPERJ/Nau Editora, 2020. p. 385-411.

LIMA, I. S. A voz e a cruz de Rita: africanas e comunicação na ordem escravista. Revista Brasileira de História, Dossiê "Por escravos", v. 38, n. 79, p. 41-63, 2018.

LIMA, I. S. Língua e diversidade: imagens sobre africanos e escravidão. História da Historiografia, v. 25, p. 44-64, 2017.

MAIA, M. De reino traficante a povo traficado. A diáspora dos courás do golfo do Benim para as minas de ouro da América Portuguesa. 1715-1760. 2013. Tese (Doutorado em História) - Universidade Federal do Rio de Janeiro, Rio de Janeiro, 2013.

NAJERA, J. de. Doctrina Chistiana. Madrid: Domingos Garcia Morras, 1658. Edição facsimilar reproduzida em LABOURET, H.; RIVET, P. Le Royaume d'Arda et son évangelisation au XVII siècle. Paris: Institut d'Ethnologie, 1929.

OLDENDORP, C. G. A. History of the Mission of the Evangelical Brethren on the Caribbean Islands of St. Thomas, St. Croix, and St. John. Ann Arbor: Karoma Publishers, 1987.

PARÉS, N. A formação do candomblé. História e ritual da nação jeje na Bahia. São Paulo: Companhia das Letras, 2007. 
PEIXOTO, A. da C. Obra nova da lingoa geral de mina, traduzida ao nosso igdioma. 1741 (Manuscrito, Biblioteca Pública de Évora).

PEIXOTO, A. da C. Alguns apontamentos da lingoa minna com as palavras portuguezas correspondentes. 1731 (Manuscrito, Seção de reservados Biblioteca Nacional de Lisboa).

PEIXOTO, A. da C. Obra nova da língua geral de Mina. Lisboa: Agência Geral das Colônias, 1944. Disponível em: https://purl.pt/16608. Acesso em: 24 nov. 2021.

PEIXOTO, A. da C. Obra nova da língua geral de Mina. Lisboa: Agência Geral das Colônias, 1945.

PETTER, M. T. Introdução à linguística africana. São Paulo: Editora Contexto, 2015.

RODRIGUES, A. Obra Nova da Lingua Geral de Mina: a língua ewe nas Minas Gerais. Papia, v. 13, p. 92-96, 2003.

RODRIGUES, A. As línguas gerais sulamericanas. Papia, v. 4, n. 2, p. 6-18, 1996.

SILVA, W. S. da. A Língua Geral de Mina e o Ciclo do Ouro: um capítulo da história dos contatos no Brasil. 2020. Tese (Doutorado em Linguística) - Faculdade de Filosofia, Letras e Ciências Humanas, Universidade de São Paulo, São Paulo, 2020.

SILVA Jr., C. A diáspora mina-gbe no mundo atlântico. In: RODRIGUES, A.; FARIAS, J. B.; LIMA, I. S. (org.). A diáspora mina: africanos entre o golfo do Benim e o Brasil. Rio de Janeiro: FAPERJ/Nau Editora, 2020. p. 21-52.

SOARES, M. de C. Devotos da cor. Identidade étnica, religiosidade e escravidão. Rio de Janeiro, século XVIII. Rio de Janeiro: Civilização Brasileira, 2000.

SOARES, M. de C. (org.). Diálogos Makii de Francisco Alves de Souza. Manuscrito de uma congregação católica de africanos Mina, 1786. São Paulo: Chão Editora, 2019.

STEINBERG, J. O historiador e a questione della lingua. In: BURKE, P.; PORTER, R. (org.). História Social da Linguagem. UNESP/Cambridge, 1997. 
- | O conceito de língua geral de Mina: apontamentos para a compreensão de seu significado histórico

SWEET, J. Domingos Alvares, African Healing, and the Intellectual History of the Atlantic Word. The University of North Carolina Press, 2011.

ZWARTJES, O. Portuguese missionary grammars in Asia, Africa and Brazil, 1550-1800. Amsterdam/Philadelphia: John Benjamins Publishing Company, 2011.

COMO CITAR ESTE ARTIGO: LIMA, Ivana Stolze. O conceito de língua geral de Mina: apontamentos para a compreensão de seu significado histórico. Revista do GEL, v. 18, n. 3, p. 143-168, 2021. Disponível em: https://revistadogel.gel.org. $\mathrm{br} /$ 